\title{
Treatment of Antibiotic Pharmaceutical Wastewater Using a Rotating Biological Contactor
}

\author{
Rongjun Su, ${ }^{1,2,3}$ Guangshan Zhang, ${ }^{2,3}$ Peng Wang, ${ }^{2}$ Shixiong Li, \\ Ryan M. Ravenelle, ${ }^{3}$ and John C. Crittenden ${ }^{3}$ \\ ${ }^{1}$ Department of Environmental Engineering, Harbin Commerce University, Harbin 150076, China \\ ${ }^{2}$ School of Municipal and Environmental Engineering, Harbin Institute of Technology, Harbin 150090, China \\ ${ }^{3}$ School of Civil and Environmental Engineering, Georgia Institute of Technology, Atlanta, GA 30332, USA \\ Correspondence should be addressed to Rongjun Su; 765806356@qq.com
}

Received 20 October 2014; Revised 29 December 2014; Accepted 2 January 2015

Academic Editor: Wenshan Guo

Copyright (C) 2015 Rongjun Su et al. This is an open access article distributed under the Creative Commons Attribution License, which permits unrestricted use, distribution, and reproduction in any medium, provided the original work is properly cited.

\begin{abstract}
Rotating biological contactors (RBC) are effective for treating wastewater, while they are rarely reported to be used for treating antibiotic pharmaceutical wastewater (APW). The current study investigates treatment of APW using an RBC. The effects of influent concentration, number of stages, and temperature on the remediation of APW were studied. The results indicated, even at low ambient temperature, $45 \% \mathrm{COD}$ and $40 \% \mathrm{NH}_{4}^{+}-\mathrm{N}$ removal efficiencies. Moreover, the $\mathrm{BOD}_{5}$ removal efficiency was $85 \%$. Microscopic observations illustrated that there were various active microorganisms displayed in the biofilms and their distribution changed from stage to stage. Compared with activated sludge, the biofilms in this study have higher content of dry matter and are easier to dehydrate and settle. Compared with current commercial incineration processes or advanced oxidation processes, $\mathrm{RBC}$ can greatly reduce the treatment cost. This research shows RBC is effective for such an inherently biorecalcitrant wastewater even at low ambient temperature.
\end{abstract}

\section{Introduction}

Biological treatment processes have been widely used in wastewater treatment for their low cost and effectiveness [1]. They are classified as either attached growth or suspended growth according to the living status of the microorganisms [2]. Activated sludge method is used mostly as an aerobic suspended growth process. Although the activated sludge method is effective for the treatment of some kinds of lowstrength pharmaceutical wastewater, it has the disadvantage of slow sludge settling [3].

The attached-growth process, also known as the biofilm process, is important for wastewater treatment and is applied in numerous areas such as groundwater treatment and municipal and hazardous wastewater treatment [4]. The rotating biological contactor (RBC) biofilm process was popularized in the 1970s. Currently, RBC is still an important biofilm process in existing treatment facilities for municipal and industrial wastewater treatment with medium strength
(COD concentration is $600-2000 \mathrm{mg} \cdot \mathrm{L}^{-1}$ ) of organic substances $[5,6]$. It has been found that the biomass composition of the discs within the RBC plays a major role in the organic biodegradation $[7,8]$. RBC has the advantages of a high concentration of microorganisms in good living and reproducing status, high efficiency for degrading organic compounds, and high suitability for fluctuations in flow rate and organic concentration $[9,10]$. RBC also has the advantages of simultaneous nitrification and denitrification accompanied by carbon removal [11, 12], low water content in the sludge making it easy to settle, easy operation, low energy consumption $[7,13]$, and comparatively small required land area which is desirable in places like China, where there is an increasing shortage of land.

Antibiotics in wastewater are of particular concern, as they can induce bacterial resistance, even at low concentrations [14]. The antibiotics residual in waste streams poses a great threat to receiving water bodies (streams, rivers, and ocean) [15]. The discharge of pharmaceutical plant effluents 
can lead to the death of fish and other marine creatures [16]. The by-products of antibiotics manufacturing and residual waste liquid are a high-strength organic wastewater which is recalcitrant to biological treatment processes. It is commonly treated by incineration in the pharmaceutical plant, but this option is only suitable for large-size enterprises because of its huge investment and large operating cost. It is estimated that treatment can cost approximately 400 yuan RMB per cubic meter, which is far more than what the medium or small size enterprises can afford $[17,18]$. Advanced oxidation processes (AOPs) are well known for the capacity to oxidize and mineralize almost any organic contaminant [19-22]. However, technical applications are still scarce because AOP processes are quite expensive [23-25] and few studies have been made involving real wastewater treatment $[1,26,27]$. Therefore, a suitable low cost process for treating real highstrength organic pharmaceutical wastewater is desirable.

In this paper, we investigate the potential of biological processes to treat wastewater containing pharmaceutical byproducts. A high-strength antibiotic pharmaceutical residual liquid was mixed with ordinary wastewater and was then treated by a simple three-stage RBC system. The treatment effect was quantified by measuring the removal of chemical oxygen demand (COD), 5-day biochemical oxygen demand $\left(\mathrm{BOD}_{5}\right)$ and ammonia nitrogen $\left(\mathrm{NH}_{4}^{+}-\mathrm{N}\right)$. In addition, the influence of some process variables was examined. The treatment cost, microbial distribution, and dehydration of the biofilms were also studied.

\section{Materials and Methods}

2.1. Analytical Methods. Analyses of $\mathrm{COD}, \mathrm{BOD}_{5}$, and $\mathrm{NH}_{4}^{+}$ $\mathrm{N}$ were carried out in order to investigate biodegradability of the pharmaceutical effluents. After comparing and rectifying according to the Chinese standard method of COD measurement, which is a titrimetric method using dichromate as the oxidant in acidic solution at $458 \mathrm{~K}$ for 2 hours, COD was determined by a COD swift measuring device because they were in agreement with the dichromate result and were much faster and easier to conduct (CTL12, Huatong, Chengde, Hebei, China). $\mathrm{BOD}_{5}$ was measured by the 5-day BOD test using the azide modification of the iodometric method for $\mathrm{DO}$ determination with a $\mathrm{BOD}_{5}$ measuring device (Type 870, Jiangsu, China) in a biochemical incubator (DHP-9162, Yiheng, Shanghai, China). $\mathrm{NH}_{4}^{+}$- $\mathrm{N}$ was determined by the titrimetric method after a preliminary distillation step in which a standard line was prepared in advance by a spectrophotometer (SP721E, Guangpu, Shanghai, China). Other technical parameters were also measured in the experiments. $\mathrm{DO}, \mathrm{pH}$, and turbidity were determined using a DO meter (JPSJ-605, Jingmi, Shanghai, China), a portable $\mathrm{pH}$ meter (PHS-25, Leici, Shanghai, China), and a turbidity meter (SGZ-2P, Qiwei, Shanghai, China) connected to a PC. Additionally, microorganisms were observed by a microscope (BS203, Guangxue, Chongqing, China).

2.2. Rotating Biological Contactor (RBC). The RBC reactor consisted of three stages with rotating biodiscs attached to

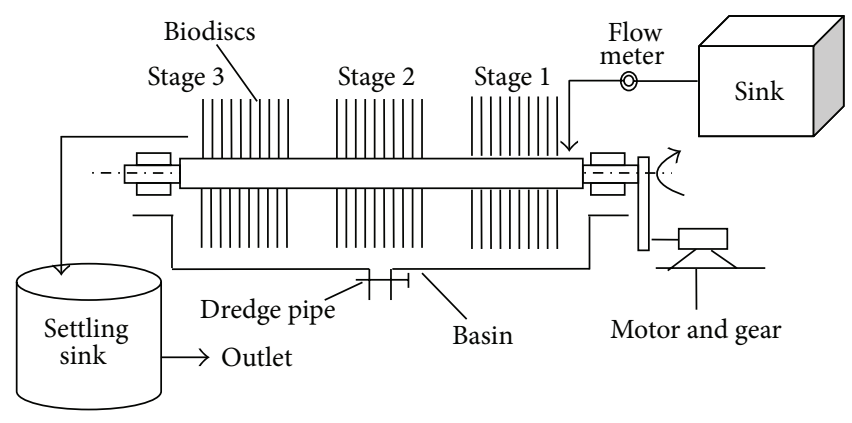

FIGURE 1: RBC treatment apparatus.

a single shaft spanning the length of the reactor (Figure 1). Each stage consisted of a group of 12 discs arranged in an oxidation basin with a working volume of $0.0172 \mathrm{~m}^{3}$. The discs were made of lightweight plastic $32 \mathrm{~cm}$ in diameter with $2 \mathrm{~cm}$ spacing between neighboring discs. They were mounted on a galvanized hollow metal shaft with $45 \%$ of the disc area submerged in liquid. The shaft was mounted in bearings attached to both ends of the RBC reactor and spins at a rate of $4 \mathrm{rpm}$ during operation. The RBC was made by Teaching Instruments Corp. of Harbin Institute of Technology.

2.3. Wastewater. Wastewater to cultivate the biofilms came from a mixture of wastewater from a cafeteria discharging (CD) and rice washing water (RWW) which was obtained from the Second Dining Hall of Harbin Commerce University. CD was filtered by a column filled with coal combustion residual particles (size: $2-6 \mathrm{~mm}$ ) and then precipitated to remove some of the suspended rough solid particles and a fraction of oily matter in the wastewater. Wastewater samples with different COD values were prepared by mixing proportions of $\mathrm{CD}$ and RWW. Pharmaceutical wastewater in the following tests was a mixture of antibiotic production residual liquid (APRL) from the workshop of a local pharmaceutical plant and either discharging sewage (DS) from the pharmaceutical plant or a mixture of RWW and natural water (NW) from a creek. The composition of APRL consists of ferment ramification, residual penicillin, and several residual menstrua including acetone, amyl butyric ester, formaldehyde, and sulfate radical with COD of 400 $000 \mathrm{mg} \cdot \mathrm{L}^{-1}$. After filtration, the characteristics of its filtrate (FAPRL) are the following: COD $320000 \mathrm{mg} \cdot \mathrm{L}^{-1}, \mathrm{pH} 4.42$, and $\mathrm{BOD}_{5} / \mathrm{COD}=0.16$. The $\mathrm{COD}, \mathrm{BOD}_{5}$, and $\mathrm{NH}_{4}^{+}$-N values of each type of raw water and their standard deviations (SD) are given in Table 1 in which the data are approximate values.

2.4. RBC Startup. Biofilms were grown naturally with activated sludge from Harbin Wenchang Sewage Treatment Plant as inoculum. The activated sludge was distributed evenly to the three oxidizing basins and wastewater was added into the basins at the same time. The concentration ratio of $\mathrm{BOD}_{5}: \mathrm{N}: \mathrm{P}: \mathrm{S}$ in the cultivation wastewater was maintained at $100: 5: 1: 1$ in which the concentration of $\mathrm{BOD}_{5}$ was $300 \mathrm{mg} \cdot \mathrm{L}^{-1}$ on average. The disks were then rotated for one day to allow microorganisms to attach to the surface of the 
TABLE 1: Characteristics of different kinds of raw water $\left(\mathrm{mg} \cdot \mathrm{L}^{-1}\right)$.

\begin{tabular}{lcccccc}
\hline & \multicolumn{2}{c}{$\mathrm{COD}, \mathrm{SD}$} & \multicolumn{2}{c}{$\mathrm{BOD}_{5}, \mathrm{SD}$} & \multicolumn{2}{c}{$\mathrm{NH}_{4}^{+}-\mathrm{N}, \mathrm{SD}$} \\
\hline CD & 300 & 6.2 & 160 & 4.1 & 12 & 0.21 \\
RWW & 40000 & 740 & 18000 & 420 & 102 & 1.8 \\
APRL & 400000 & 7600 & - & & - & \\
FAPRL & 320000 & 5100 & 51000 & 1100 & 930 & 16 \\
DS & 350 & 6.5 & 120 & 3.1 & 18 & 0.31 \\
NW & 20 & 0.42 & 7 & 0.16 & 3 & 0.046 \\
\hline
\end{tabular}

discs. In order to satisfy the nutrient needs of the microorganisms, $2 / 3$ of the supernatant in the basins was replaced every day. The COD of newly added wastewater was 1000 $2000 \mathrm{mg} \cdot \mathrm{L}^{-1}$. After one week of operation, biofilms $2-3 \mathrm{~mm}$ thick were formed. The biofilms had many nematodes and rotifers, which indicates that there was oxygen being supplied to the biofilm. After the biofilms were fully formed, the RBC was run continuously. The input wastewater had a $\mathrm{pH}$ of 6-8 and the flow rate to the oxidation basins was $16 \mathrm{~L} \cdot \mathrm{h}^{-1}$ with a hydraulic retention time of 1.29 hours for the whole threebasin cycle. $90 \mathrm{~L}$ of pharmaceutical wastewater was mixed with $30 \mathrm{~L}$ of treated waste water that remained in the 3 stages. (Figure 1). Ambient temperature varied from $10^{\circ} \mathrm{C}$ to $16^{\circ} \mathrm{C}$. The whole experiments lasted more than three months.

2.5. RBC Experiment. After the biofilm was well formed, the $\mathrm{RBC}$ apparatus was used to treat the cafeteria wastewater to initially verify treatment effectiveness. The COD removal ratio was $70 \%-80 \%$ on average and the $\mathrm{NH}_{4}^{+}$- $\mathrm{N}$ elimination ratio was over $80 \%$ on average. Then the pharmaceutical wastewater which consisted of APRL and DS was gradually added to the basins to acclimate the microorganisms. After two weeks of successful cultivation, the treatment of pharmaceutical wastewater consisting of FAPRL diluted by NW and added additionally ca. $0.5 \%$ (v:v) RWW as a nutrition to keep a suitable $\mathrm{B} / \mathrm{C}\left(\mathrm{BOD}_{5} / \mathrm{COD}>3.5\right)$ was carried out. This wastewater was used in the subsequent experiments and had an average COD of $800 \mathrm{mg} \cdot \mathrm{L}^{-1}$. Samples of the influent and effluent of the RBC were usually taken at $0.5 \mathrm{~h}$ and $1.8 \mathrm{~h}$ after refreshing the wastewater, respectively.

2.6. Features of Biofilms. Microbial growth and distribution in the biofilms was observed with a microscope to see whether the microorganisms were the needed and whether they worked well. The thicknesses were measured with a simple slide caliper.

The dehydration tests and the measurements of dry and moist weight of the biofilms were carried out as follows. The biofilms were peeled from the discs and allowed to dry at ambient conditions. The samples were weighed, then centrifuged for $10 \mathrm{~min}$ at $1600 \mathrm{rpm}$, removed, drained, and weighed again. Finally, they were heated for $2 \mathrm{hrs}$ at $105^{\circ} \mathrm{C}$ and weighed again.

\section{Results and Discussions}

3.1. Acclimation of Biofilms. After successful treatment of the cafeteria wastewater with RBC, the rate of pharmaceutical

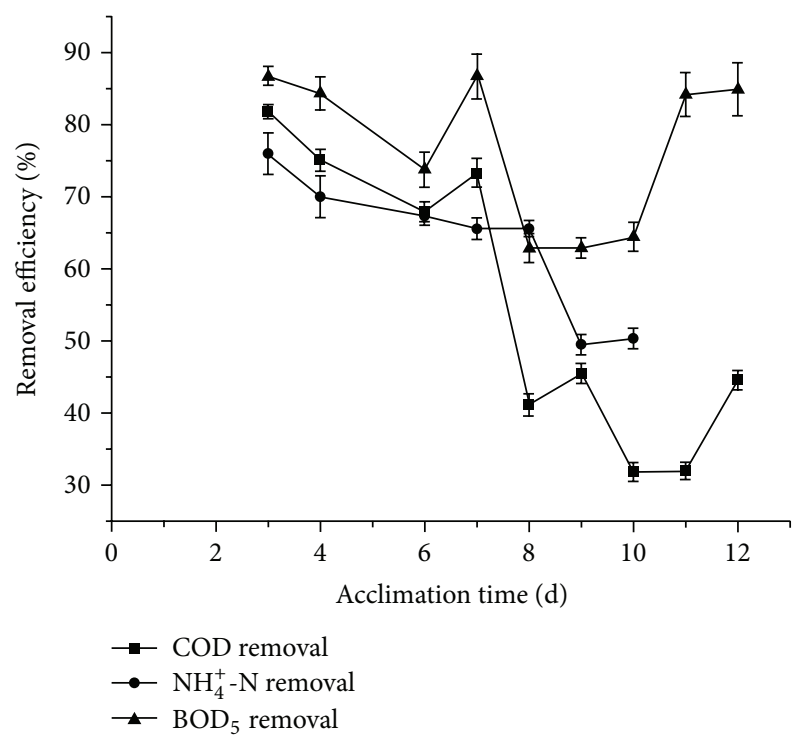

FIgURE 2: Changes of $\mathrm{COD}, \mathrm{NH}_{4}^{+}-\mathrm{N}$, and $\mathrm{BOD}_{5}$ removal efficiency over time and their standard deviations.

wastewater addition was gradually increased over a period of 14 days to carry out the acclimation experiment. Between the 8 th and 10th day, the $\mathrm{BOD}_{5}$ removal quickly dropped, so the incremental addition of pharmaceutical wastewater was decreased from the initial $8 \%$ per day to $6 \%$ per day. The rate of pharmaceutical wastewater addition in the acclimation process was $7 \%$ on average per day.

The $\mathrm{COD}, \mathrm{NH}_{4}^{+}-\mathrm{N}$, and $\mathrm{BOD}_{5}$ removal efficiency as a function of acclimation time and their standard deviations are shown in Figure 2.

3.1.1. Changes of COD Removal Efficiency. It can be seen that, with the acclimation of the biofilms, the COD removal decreased from $80 \%$ to $40 \%$ over 9 days and fluctuated slightly around $40 \%$ thereafter. It can be concluded that the quantity and kinds of bacteria or fungus and so forth heterotrophs in the attached biofilms of the RBC changed and began acclimatizing themselves to new wastewater or reproduced variations suitable for new wastewater, after which the COD removal stabilized at $40 \%$. The main reason for the decreasing COD removal is that, with the gradual addition of pharmaceutical wastewater, there is an increasing quantity of biorecalcitrant substances and increasing toxicity of wastewater which results in intensified shock and toxicity to bacteria or fungus and so forth beyond their treating and endurance capability. Another reason is the low ambient temperature during the acclimation period which varied from $10^{\circ} \mathrm{C}$ to $16^{\circ} \mathrm{C}$. The low temperature is difficult to avoid since the whole RBC apparatus cannot be heated. At low temperature, the biodegradation rate decreased as expected $[3,16]$.

3.1.2. Changes of $\mathrm{NH}_{4}^{+}-\mathrm{N}$ Removal Efficiency. Figure 2 also shows that, with elapsed acclimation time, the $\mathrm{NH}_{4}^{+}-\mathrm{N}$ removal efficiency declines from about $70 \%$ to $50 \%$ over 11 days, after which it remains stable. Although $\mathrm{NH}_{4}^{+}-\mathrm{N}$ 
were removed by autotrophs being different from COD's removal by heterotrophs with the exception of heterotrophic nitrifiers, increasing toxicity of wastewater and low ambient temperature may be the main reasons leading to low activity of both autotrophs and heterotrophs. Consequently $\mathrm{NH}_{4}^{+}$$\mathrm{N}$ removal is declined. These reasons are similar to the abovementioned reasons resulting in the decreased COD removal.

3.1.3. Changes of $B O D_{5}$ Removal Efficiency. The changes of $\mathrm{BOD}_{5}$ removal during acclimation are also shown in Figure 2. As the addition of pharmaceutical wastewater increased, the $\mathrm{BOD}_{5}$ removal decreased to around $60 \%$. This is because the rate of pharmaceutical wastewater addition was increasing too fast compared to the initial addition rate and the microorganisms were unable to adapt in time. When the additive amount of pharmaceutical wastewater was adjusted and acclimation period became longer, the removal of $\mathrm{BOD}_{5}$ began to rise to approximately $85 \%$ in the end. This indicates that the microorganisms in the biofilms gradually adapted to pharmaceutical wastewater and they efficiently removed the biodegradable organics.

The results of the abovementioned experiments show that, even at low ambient temperature, the RBC method is effective for treating pharmaceutical wastewater. This indicates that this RBC technology can potentially be used in frigid areas.

\subsection{Treatment of Pharmaceutical Wastewater with RBC.} After acclimation, the effect of influent COD concentration on the $\mathrm{COD}, \mathrm{NH}_{4}^{+}-\mathrm{N}$, and $\mathrm{BOD}_{5}$ removal from pharmaceutical wastewater was investigated. The effect of different influent concentration on the $\mathrm{COD}, \mathrm{NH}_{4}^{+}-\mathrm{N}$, and $\mathrm{BOD}_{5}$ removal and their standard deviations is shown in Figure 3.

3.2.1. Effect of Influent Concentration on COD Removal. The COD removal efficiencies are within $45-50 \%$ when organic input concentration was below $1100 \mathrm{mg} \cdot \mathrm{L}^{-1}$. With an increase of organic input concentration from 400 to $800 \mathrm{mg} \cdot \mathrm{L}^{-1}$, the COD removal increased slightly. The overall COD removal was not high compared with the results of treating sewage wastewater. This is attributed to the fact that there are biorecalcitrant substances in the pharmaceutical wastewater [18]. Another reason is related to the low ambient temperature. It has been reported that, with rising ambient temperature, the COD removal efficiencies of different kinds of wastewater improve accordingly [20,27].

\subsubsection{Effect of Influent Concentration on $\mathrm{NH}_{4}^{+}-\mathrm{N}$ Removal.} The effect of influent concentration on $\mathrm{NH}_{4}^{+}-\mathrm{N}$ removal is also shown in Figure 3.

It is seen that the $\mathrm{NH}_{4}^{+}-\mathrm{N}$ removal efficiencies declined with increasing influent concentration. The literature reports that there will be rapid decline in $\mathrm{pH}$ as nitrification proceeds [28]. We also found that the $\mathrm{pH}$ declined in our experiments. Nitrifying bacteria are sensitive to the changes in $\mathrm{pH}$ of wastewater in the process of nitrification. In order to keep the proper activity of nitrifying bacteria, wastewater should

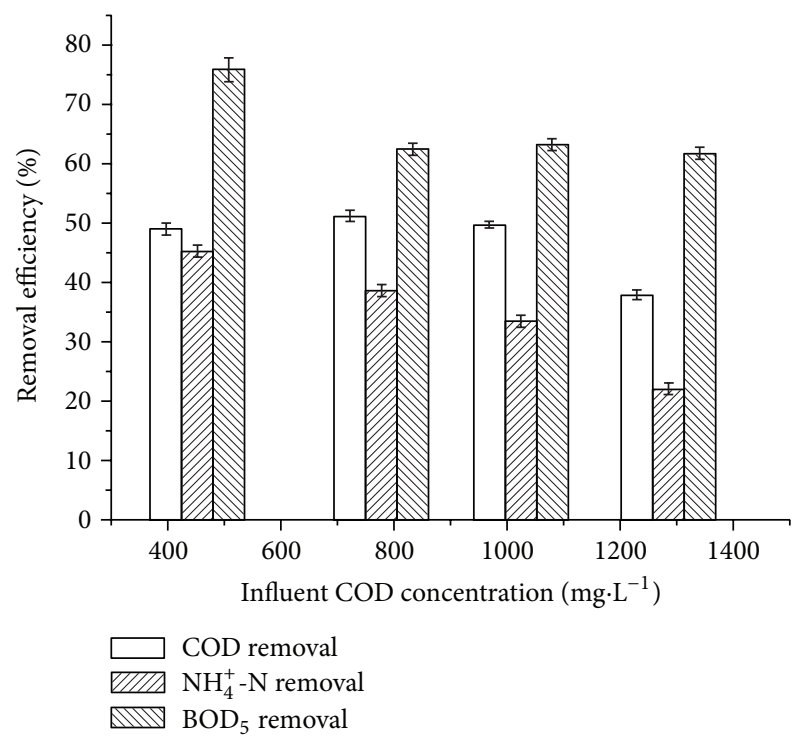

FIGURE 3: Effect of influent concentration on the COD, $\mathrm{NH}_{4}^{+}-\mathrm{N}$, and $\mathrm{BOD}_{5}$ removal and their standard deviations.

have enough alkalinity to maintain the $\mathrm{pH}$ from 7 to 8.2 . It was reported that a fully submerged closed-RBC resulted in high denitrification rate and produced half of the alkalinity consumed by nitrification $[29,30]$. In our experiments, the treated wastewater and biodiscs were exposed to the low temperature ambient air, resulting in a relative aerobic environment which was different from the above mentioned submerged closed-RBC environment. This led to little denitrification occurrence. Furthermore, there was little residual alkalinity to maintain the $\mathrm{pH}$ of wastewater resulting in possible $\mathrm{pH}$ fluctuations. This exerts a significant influence on the nitrification of nitrifying bacteria which can lead to a low $\mathrm{NH}_{4}^{+}-\mathrm{N}$ removal efficiency $[9,11]$. Another reason why $\mathrm{NH}_{4}^{+}$-N removal efficiency declined is that only $\mathrm{NH}_{4}^{+}$-N was measured; therefore, the whole change and transfer process of $\mathrm{N}$ in wastewater was unknown. It is possible that there was a high organic- $\mathrm{N}$ content in wastewater and the degraded rate of organic-N was more than that of $\mathrm{NH}_{4}^{+}-\mathrm{N}$. This would lead to the production of $\mathrm{NH}_{4}^{+}-\mathrm{N}$ by the heterotrophs and a lower $\mathrm{NH}_{4}^{+}-\mathrm{N}$ removal efficiency.

3.2.3. Effect of Influent Concentration on $\mathrm{BOD}_{5}$ Removal. In order to investigate the biodegradability of pharmaceutical wastewater, the $\mathrm{BOD}_{5}$ values of the inlet and outlet water were measured (Figure 3 ) and ratios of $\mathrm{BOD}_{5} / \mathrm{COD}$ were calculated below.

The $\mathrm{BOD}_{5}$ removal efficiency decreased initially with increasing influent concentration, and then it stabilized at about $60 \%$. In experiments we also measured that the ratios of $\mathrm{BOD}_{5} / \mathrm{COD}$ in the abovementioned 4 experiments in Figure 3 declined accordingly from $0.31,0.41,0.43$, and 0.44 to values of $0.15,0.31,0.29$, and 0.27 , respectively. This means that most of the biodegradable content in the pharmaceutical wastewater was decomposed by microorganisms. Because of the existence of some biorecalcitrant and toxic substances and 
the low ambient temperature, the microorganisms in biofilms cannot effectively degrade all of the organics in wastewater which has an influence on the $\mathrm{BOD}_{5}$ removal to some extent.

From the abovementioned effects of influent concentration on $\mathrm{COD}, \mathrm{NH}_{4}^{+}-\mathrm{N}$, and $\mathrm{BOD}_{5}$ removal, we draw the conclusion that the influent concentration does not significantly affect organic removal. This is mainly ascribed to the fact that there are multiple stages in the RBC. The initial stage effectively buffers the shock of influent concentration and toxins. Another reason for resistance to high influent concentration is that the biofilms have a thickness of $0.5-3 \mathrm{~mm}$, and the shock of input organics or toxins impact the inner layer of the biofilms less than the outer layer, thus leaving a relatively active inner layer. Thus it is difficult to destroy a whole piece of biofilm from one disc or all the biofilms from all disks in 3 stages. Therefore, RBC is capable of resisting the impact of influent concentration fluctuation. This means that RBC has a stronger suitability for the concentration shock of wastewater compared with activated sludge process. After such a shock, it can restore its function rapidly. However, compared with activated sludge process, it is only suitable for wastewater with low influent concentration. Because, generally speaking aerobic biofilms process can only treat waste water with a low COD concentration as $600-1500 \mathrm{mg} \cdot \mathrm{L}^{-1}$ which is lower than that of aerobic activated sludge method as $800-2000 \mathrm{mg} \cdot \mathrm{L}^{-1}$, anaerobic biological process can treat waste water with a high COD loading as $8000-15000 \mathrm{mg} \cdot \mathrm{L}^{-1}$ [16].

The changes of dissolved oxygen (DO), turbidity, and temperature between influent and effluent were measured and are displayed in Table 2 .

We also measured and found the temperature of the wastewater in the basins dropped gradually downstream. The influent was heated by a heating apparatus in sink and to a temperature of $18-20^{\circ} \mathrm{C}$, but there was not any heating apparatus in basin. When it flowed into basin, it became cool because of cold ambient air. The drop of water temperature would partly lead to the increase of DO. Another reason was that, with the decrease of $\mathrm{COD}$ and $\mathrm{BOD}_{5}$ downstream, metabolic activities of microorganisms decreased and their oxygen consumption decreased. This left more oxygen in the effluent. In addition, the RBCs are very good at reaerating the water.

The effect of temperature on the reaction rate of aerobic biodegradation is given as follows [3]:

$$
K_{T}=K_{20} \cdot \theta^{(T-20)}
$$

where $T$ is temperature $\left({ }^{\circ} \mathrm{C}\right)$ of wastewater, $\theta=1.047$ (when $T=10-35^{\circ} \mathrm{C}$ ), and $K_{20}$ is the aerobic biodegradation rate constant at $20^{\circ} \mathrm{C}$. From this equation, it can be shown that $K_{10} / K_{20}$ is 0.638 implying that the biodegradation rate drops significantly from $20^{\circ} \mathrm{C}$ to $10^{\circ} \mathrm{C}$. Therefore, the ambient temperature has a significant effect on treatment efficacy with higher temperature leading to more effective treatment. These results are similar to the experiments of the effect of treating cafeteria wastewater with this RBC [31].

In our experiments, the biofilms in 1st stage dropped off and were replaced during 20-25 days while the biofilms in 2nd stage and 3rd were maintained well up to 40-60 days.
TABLE 2: Changes of several technical values before and after treatment.

\begin{tabular}{lccc}
\hline $\begin{array}{l}\text { Sample } \\
\text { position }\end{array}$ & $\begin{array}{c}\text { DO } \\
\left(\mathrm{mg} \cdot \mathrm{L}^{-1}\right)\end{array}$ & $\begin{array}{c}\text { Turbidity } \\
(\mathrm{NTU})\end{array}$ & $\begin{array}{c}\text { Temperature } \\
\left({ }^{\circ} \mathrm{C}\right)\end{array}$ \\
\hline Influent & $0.8 \sim 2.2$ & $60 \sim 120$ & $18 \sim 20$ \\
Effluent & $4.6 \sim 7.2$ & $15 \sim 28$ & $10 \sim 12$ \\
\hline
\end{tabular}

It was reported that attrition rather than sloughing is the prevailing biomass loss mechanism [32]. According to the loss amount of biomass in basin, the sludge age was roughly 28-35 days. F/M ratio was $0.05-0.15 \mathrm{kgBOD}_{5} \cdot \mathrm{kgMLSS}^{-1} \cdot \mathrm{d}^{-1}$ with an average around $0.10 \mathrm{kgBOD}_{5} \cdot \mathrm{kgMLSS}^{-1} \cdot \mathrm{d}^{-1}$.

Other factors such as the spinning speed of the biodiscs, the quality of biodiscs material, hydraulic retention time, and hydraulic loading also influence the treatment effectiveness though these variables were not considered in this study [11, $12,33]$.

\subsection{Study on Features of the Biofilms in the RBC}

3.3.1. Microbial Growth and Distribution in Biofilm. After examining the biofilms under a microscope, it was noted that fungus often appeared in the biofilms. Because of their silky structure, they can improve the biofilm structure and promote its growth. In addition, bacteria can attach to the surface of silky fungus. However, if there is too much fungus, this will lead to excessive film thickness. Periodic microscope inspections showed that there were a lot of bacteria and mycelia and also plenty of active protists and metazoa in the biofilms, such as epistylis, opercularia, ciliata, amoebas, nematodes, and rotifers. This indicated that the microorganisms were the needed species and they grew well. Moreover, proceeding from stages 1,2 , and 3 , an increased number of protists and metazoa were observed in stage 3 . On the contrary, they seldom appeared in stage 1 . The overall quantity of microorganisms which were mainly bacteria, fungus, and mycelia in the stage 1 biodiscs was also greater than that of the stage 3 discs. This indicated that the distribution of microorganisms changed from stage to stage to some extent. This conforms to the common pattern of microorganisms distribution in wastewater treatment by biofilm process.

\subsubsection{Study on Quantity of Biofilms}

Thickness of Biofilms. The thickness differed from $0.1 \mathrm{~mm}$ to $3 \mathrm{~mm}$ according to different conditions and periods. Due to uneven nutrient distribution in the different biodiscs, the thicknesses of the biofilms at a given time varied depending on location in the RBC. Generally speaking, the biofilms on the upstream biodiscs were thicker than the downstream ones. Proper thickness should be about $2 \mathrm{~mm}$. If too thick, there may be excessive anaerobic biodegradation and consequently a release of unpleasant odor. Even more, endogenous metabolism may take place resulting in the loss of adhesion of the biofilms which may cause them to separate from the biodiscs. 
TABLE 3: Weight $(W)$ and water ratio of biofilm on single disc and removal percentages in different stages.

\begin{tabular}{|c|c|c|c|c|c|c|c|c|c|c|}
\hline \multirow{2}{*}{$\begin{array}{l}\text { Stage } \\
1 \text { st }\end{array}$} & \multicolumn{2}{|c|}{ Wet $W$, SD (g) } & \multicolumn{2}{|c|}{ Dry $W$, SD (g) } & \multirow{2}{*}{$\begin{array}{c}\text { Dry } W \\
\left(\mathrm{~g} / \mathrm{m}^{2}\right)\end{array}$} & \multirow{2}{*}{$\begin{array}{c}\begin{array}{c}\text { Water ratio } \\
(\%)\end{array} \\
97.46\end{array}$} & \multicolumn{2}{|c|}{$\begin{array}{c}\mathrm{COD}, \mathrm{SD} \\
\text { removal (\%) }\end{array}$} & \multicolumn{2}{|c|}{$\begin{array}{l}\mathrm{BOD}_{5}, \mathrm{SD} \\
\text { removal (\%) }\end{array}$} \\
\hline & 166.93 & 2.81 & 4.24 & 0.0672 & & & 48.6 & 0.66 & 51.4 & 0.68 \\
\hline 2nd & 84.76 & 1.62 & 2.37 & 0.0361 & 14.8 & 97.20 & 30.9 & 0.37 & 31.2 & 0.42 \\
\hline $3 \mathrm{rd}$ & 45.99 & 0.843 & 1.60 & 0.0233 & 10.0 & 96.52 & 20.5 & 0.24 & 17.4 & 0.30 \\
\hline
\end{tabular}

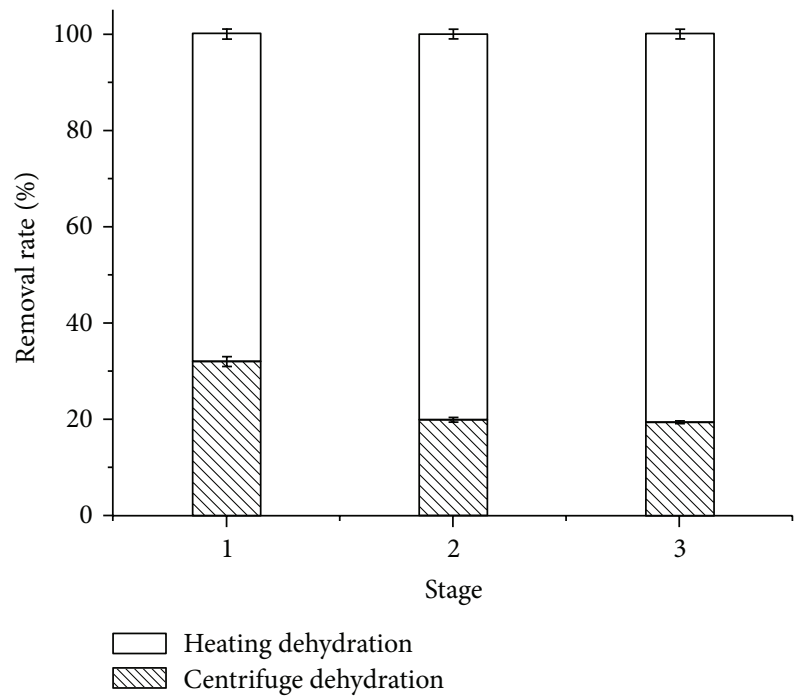

FIGURE 4: Heating and centrifugal dehydration removal efficiencies and standard deviations for each RBC stage.

Dehydration of Biofilms. The results of dehydration of the biofilms with centrifugal and heat treatment processes are shown in Figure 4.

The results indicate that centrifugal dehydration can remove $20 \%-30 \%$ of the absorbed water in the biofilms, while complete dehydration requires heating at $105^{\circ} \mathrm{C}$ for ca. $2 \mathrm{hrs}$. Compared with the sludge in activated sludge process [2], the biofilms have a higher centrifugal dehydration ratio which means they are easy to dehydrate. This is important for treatment of wastewater. It also can be seen that the centrifugal dehydration ratio of the first stage is far more than that of the second and third. This shows the biofilms in the first stage are more easily dehydrated and have a less compact structure. On the experiments, we also found that biofilm pieces dropped in the first stage were usually bigger than that in the second or third stage. Therefore they were also easy to settle although they have a less compact structure.

Weight of Biofilms. The results of dry and wet weight of the biofilms in different stage and their corresponding COD and $\mathrm{BOD}_{5}$ removal percentages in the total removal efficiencies are given in Table 3.

After wastewater flows into the RBC apparatus, the organic compounds are gradually degraded by microorganisms. There is higher organic content in wastewater near the inlet which makes microorganisms reproduce faster. On the contrary, there is relative less organic content in the downstream stages resulting in lower content of microorganisms. Therefore, as the water proceeds downstream, the concentration of microorganisms on the stage reduces. Compared with the sludge in activated sludge processes [17], the content of dry matter in the biofilms is higher and the biofilms have a higher density which is easy to settle.

3.4. Cost Analysis. According to the technologies of advanced oxidation processes (AOPs) of pharmaceutical wastewater reported in related literature $[18,19,21]$, the cost of handling this kind of high-strength pharmaceutical reactor residual or waste liquid can be estimated. In their study, the COD removal efficiency usually reached $60-80 \%$ that is better than only with RBC treatment. The cost of treating such wastewater with direct incineration processes (DIPs), which is used commercially, can be attained from the pharmaceutical plant in Harbin. The effluent treated by mixing and diluting such a pharmaceutical wastewater followed by RBC treatment cannot meet the state discharging standards (first level: $100 \mathrm{mg} \cdot \mathrm{L}^{-1}$ for pharmaceutical discharging waste water). Therefore, the effluent needs to be treated further by AOP technologies in order to satisfy the state standards. The rough cost of this kind of united technology can also be calculated. The rough analysis on operating cost of these several processes is exhibited in Table 4 . The total cost consisted of fees of raw material, management and running, and depreciation annually of fixed investment. Their calculations were based on the same COD removal efficiency.

As shown in Table 4, the RBC technology in this paper can significantly reduce treatment cost compared with wholly AOPs reported or DIPs used currently.

This research is helpful for later study to attain an optimum combination of AOP and RBC to achieve the mineralization and detoxification of a real pharmaceutical wastewater.

\section{Conclusions}

In this paper, we studied the effect on disposal of residual waste liquid from an antibiotic pharmaceutical workshop with $\mathrm{RBC}$ and examined the influence of some process variables.

For this kind of biorecalcitrant waste liquid, a simple RBC apparatus can achieve $85 \% \mathrm{BOD}_{5}$ removal, $45 \% \mathrm{COD}$ removal, and an average value of $40 \% \mathrm{NH}_{4}^{+}-\mathrm{N}$ removal even at low ambient temperature of $10^{\circ} \mathrm{C}$ to $15^{\circ} \mathrm{C}$. However, after $\mathrm{RBC}$ treatment there remains some residual organic matter that cannot be removed biologically. 
TABLE 4: The rough analysis on running cost of several different processes (RMB¥ $\left./ \mathrm{m}^{3}\right)$.

\begin{tabular}{lccc}
\hline Process & Raw material & $\begin{array}{c}\text { Management } \\
\text { and running }\end{array}$ & $\begin{array}{c}\text { Shared } \\
\text { depreciation } \\
\text { of fixed investment }\end{array}$ \\
\hline Wholly AOPs & $\begin{array}{c}135 \text { (oxidant, } \\
\text { etc.) }\end{array}$ & 15 & 10 \\
RBC + AOPs & $\begin{array}{c}54 \text { (oxidant, } \\
\text { etc.) }\end{array}$ & 28 (including \\
power) & 240 (fuel, etc.) & 20 & 18 \\
DIPs & & 160 & 100 \\
\hline
\end{tabular}

In our experiments the main factors affecting treatment of $\mathrm{RBC}$ include the kind of wastewater, influent concentration, stages of RBC, and temperature.

This RBC technology reduces organic concentration significantly which is advantageous for potential latter AOP treatments. Compared with wholly AOPs or currently used DIPs, a coupled RBC-AOP treatment method can significantly decrease treatment cost.

Microscope observations show that there are plenty of different kinds of active microorganisms in the biofilm in all 3 stages.

The dehydration experiments on the biofilms indicate that centrifugal dehydration can remove $20 \%-30 \%$ of water and heating dehydration removes $70 \%-80 \%$. Compared with activated sludge in suspended growth processes, the biofilms have a higher centrifugal/heating dehydration ratio. The dry weights of biomass on the biodiscs in each of the three stages of $\mathrm{RBC}$ are $26.5 \mathrm{~g} / \mathrm{m}^{2}, 14.8 \mathrm{~g} / \mathrm{m}^{2}$, and $10.0 \mathrm{~g} / \mathrm{m}^{2}$, respectively. Compared with the activated sludge in suspended growth processes, the content of dry matter in the biofilms is higher which also indicates the biofilms are easy to settle and dehydrate.

\section{Conflict of Interests}

The authors declare no conflict of interests in the research.

\section{Acknowledgments}

The work was supported by the Provincial Natural Science Foundation of Heilongjiang (B200813), China, and China Postdoctoral Science Foundation (2014M561356). Rongjun $\mathrm{Su}$ also thanks China Scholarship Council for providing visiting opportunity at Georgia-Tech in USA. The authors also acknowledge the support of the Brook Byers Institute for Sustainable Systems.

\section{References}

[1] C. Sirtori, A. Zapata, I. Oller, W. Gernjak, A. Agüera, and S. Malato, "Decontamination industrial pharmaceutical wastewater by combining solar photo-Fenton and biological treatment," Water Research, vol. 43, no. 3, pp. 661-668, 2009.

[2] H. Shi, H. J. Zheng, D. H. Zhao, and Z. L. Wu, "Treatment of nisin production wastewater by biochemical method," Chinese Journal of Environment Engineering, vol. 2, no. 10, pp. 1369-1372, 2008 (Chinese).
[3] W. W. Eckenfelder Jr., Industrial Water Pollution Control, McGraw-Hill, New York, NY, USA, 3rd edition, 2000.

[4] G. Najafpour, H. A. Yieng, H. Younesi, and A. Zinatizadeh, "Effect of organic loading on performance of rotating biological contactors using Palm Oil Mill effluents," Process Biochemistry, vol. 40, no. 8, pp. 2879-2884, 2005.

[5] J. C. Akunna and C. Jefferies, "Performance of family-size sequencing batch reactor and rotating biological contactor units treating sewage at various operating conditions," Water Science and Technology, vol. 41, no. 1, pp. 97-104, 2000.

[6] N. Vidal, R. Bañares-Alcántara, I. Rodríguez-Roda, and M. Poch, "Design of wastewater treatment plants using a conceptual design methodology," Industrial and Engineering Chemistry Research, vol. 41, no. 20, pp. 4993-5005, 2002.

[7] A. Torkian, O. Yazdani, and K. Alinejad, “Treatability evaluation of municipal wastewater and anaerobically-treated industrial effluent in a rotating biological contactor," Industrial Journal of Engineering, vol. 16, no. 6, pp. 16-22, 2003.

[8] W. Zheng, X.-M. Li, Z.-M. Hao, D.-B. Wang, Q. Yang, and G.M. Zeng, "Coal cinder filtration as pretreatment with biological processes to treat pharmaceutical wastewater," Water Science and Technology, vol. 62, no. 1, pp. 15-20, 2010.

[9] Z. Chen, Q. Wen, J. Wang, and F. Li, "Simultaneous removal of carbon and nitrogen from municipal-type synthetic wastewater using net-like rotating biological contactor (NRBC)," Process Biochemistry, vol. 41, no. 12, pp. 2468-2472, 2006.

[10] K. Wang, S. Liu, Q. Zhang, and Y. He, "Pharmaceutical wastewater treatment by internal micro-electrolysis-coagulation, biological treatment and activated carbon adsorption," Environmental Technology, vol. 30, no. 13, pp. 1469-1474, 2009.

[11] D. N. Hiras, I. D. Manariotis, and S. G. Grigoropoulos, "Organic and nitrogen removal in a two-stage rotating biological contactor treating municipal wastewater," Bioresource Technology, vol. 93, no. 1, pp. 91-98, 2004.

[12] A. Tawfik, A. Klapwijk, F. El-Gohary, and G. Lettinga, "Potentials of using a rotating biological contactor (RBC) for posttreatment of anaerobically pre-treated domestic wastewater," Biochemical Engineering Journal, vol. 25, no. 1, pp. 89-98, 2005.

[13] B. K. Taşeli, C. F. Gökçay, and A. Gürol, "Influence of nickel (II) and chromium (VI) on the laboratory scale rotating biological contactor," Journal of Industrial Microbiology and Biotechnology, vol. 35, no. 9, pp. 1033-1039, 2008.

[14] F. Hernández, J. V. Sancho, M. Ibáñez, and C. Guerrero, "Antibiotic residue determination in environmental waters by LC-MS," TrAC-Trends in Analytical Chemistry, vol. 26, no. 6, pp. 466-485, 2007.

[15] B. Pauwels and W. Verstraete, "The treatment of hospital wastewater: an appraisal," Journal of Water and Health, vol. 4, no. 4, pp. 405-416, 2006. 
[16] G. Chen, D. Y. Li, and G. M. Zhang, “Treatment technologies for highly concentrated refractory organic wastewater," Industrial Water Treatment, vol. 23, no. 3, pp. 10-14, 2003 (Chinese).

[17] G. Tchobanoglous, F. L. Burton, and H. D. Stensel, Wastewater Engineering, Treatment, Disposal and Reuse, Metcalf \& EddyMcGraw-Hill, 4th edition, 2003.

[18] Y. Yang, P. Wang, S. Shi, and Y. Liu, "Microwave enhanced Fenton-like process for the treatment of high concentration pharmaceutical wastewater," Journal of Hazardous Materials, vol. 168, no. 1, pp. 238-245, 2009.

[19] C. Blöcher, "Elimination of micropollutants and hazardous substances at the source in the chemical and pharmaceutical industry," Water Science and Technology, vol. 56, no. 12, pp. 119123, 2007.

[20] M. I. Badawy, R. A. Wahaab, and A. S. El-Kalliny, "Fentonbiological treatment processes for the removal of some pharmaceuticals from industrial wastewater," Journal of Hazardous Materials, vol. 167, no. 1-3, pp. 567-574, 2009.

[21] H. J. José, W. Gebhardt, R. F. P. M. Moreira, J. Pinnekamp, and H. F. Schröder, "Advanced oxidation processes for the elimination of drugs resisting biological membrane treatment," Ozone: Science \& Engineering, vol. 32, no. 5, pp. 305-312, 2010.

[22] G. Mascolo, G. Laera, A. Pollice et al., "Effective organics degradation from pharmaceutical wastewater by an integrated process including membrane bioreactor and ozonation," Chemosphere, vol. 78, no. 9, pp. 1100-1109, 2010.

[23] Y. Topalova, "Biological control and management of the detoxication wastewater treatment technologies," Hemijska Industrija, vol. 61, no. 5, pp. 213-221, 2007.

[24] T. M. Smook, H. Zho, and R. G. Zytner, "Removal of ibuprofen from wastewater: comparing biodegradation in conventional, membrane bioreactor, and biological nutrient removal treatment systems," Water Science and Technology, vol. 57, no. 1, pp. $1-8,2008$.

[25] A. Zapata, I. Oiler, R. Gallay et al., "Comparison of photo-fenton treatment and coupled photo-fenton and biological treatment for detoxification of pharmaceutical industry contaminants," Journal of Advanced Oxidation Technologies, vol. 11, no. 2, pp. 261-269, 2008.

[26] A. K. Gautam, S. Kumar, and P. C. Sabumon, "Preliminary study of physico-chemical treatment options for hospital wastewater," Journal of Environmental Management, vol. 83, no. 3, pp. 298306, 2007.

[27] W. Gebhardt and H. F. Schröder, "Liquid chromatography(tandem) mass spectrometry for the follow-up of the elimination of persistent pharmaceuticals during wastewater treatment applying biological wastewater treatment and advanced oxidation," Journal of Chromatography A, vol. 1160, no. 1-2, pp. 34-43, 2007.

[28] A. A. Randall, "Contrast of volatile fatty acid driven and inorganic acid or base driven phosphorus release and uptake in enhanced biological phosphorus removal," Water Environment Research, vol. 84, no. 4, pp. 305-312, 2012.

[29] P. Teixeira and R. Oliveira, "Denitrification in a closed rotating biological contactor: effect of disk submergence," Process Biochemistry, vol. 37, no. 4, pp. 345-349, 2001.

[30] V. Oyanedel-Craver, V. Lazarova, J. M. Garrido, and R. Mendez, "Comparative study between a hybrid system and a biofilm system for the treatment of ammonia and organic matter in wastewaters," Journal of Environmental Engineering, vol. 135, no. 5, pp. 351-358, 2009.
[31] R. J. Su, "Study on treatment of canteen wastewater using rotating biological contactor," Advanced Materials Research, vol. 113-116, pp. 1597-1600, 2010.

[32] R. Delatolla, N. Tufenkji, Y. Comeau, A. Gadbois, D. Lamarre, and D. Berk, "Effects of long exposure to low temperatures on nitrifying biofilm and biomass in wastewater treatment," Water Environment Research, vol. 84, no. 4, pp. 328-338, 2012.

[33] G. Ayoub, P. Saikaly, M. Ei-Fadel, and E. Baydoun, "Impact of step-feed on $\mathrm{COD}$ and $\mathrm{BOD}_{5}$ removal in rotating biological contactors," Environmental Engineering Science, vol. 21, no. 5, pp. 558-568, 2004. 

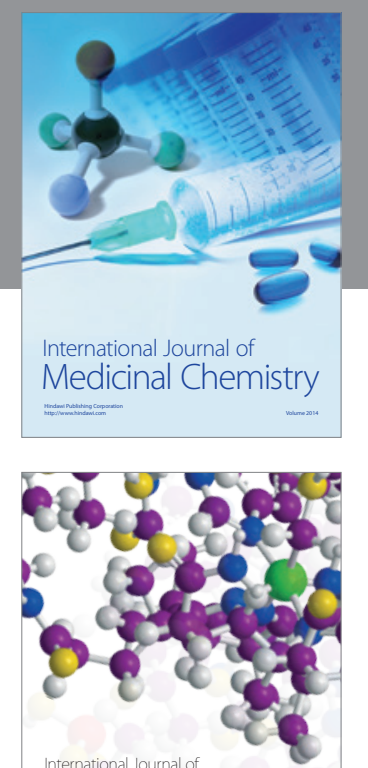

\section{Carbohydrate} Chemistry

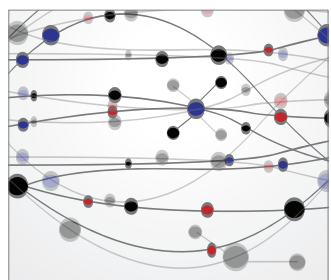

The Scientific World Journal
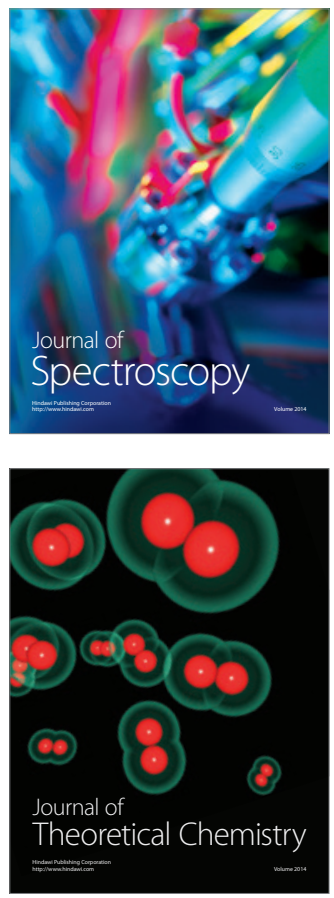
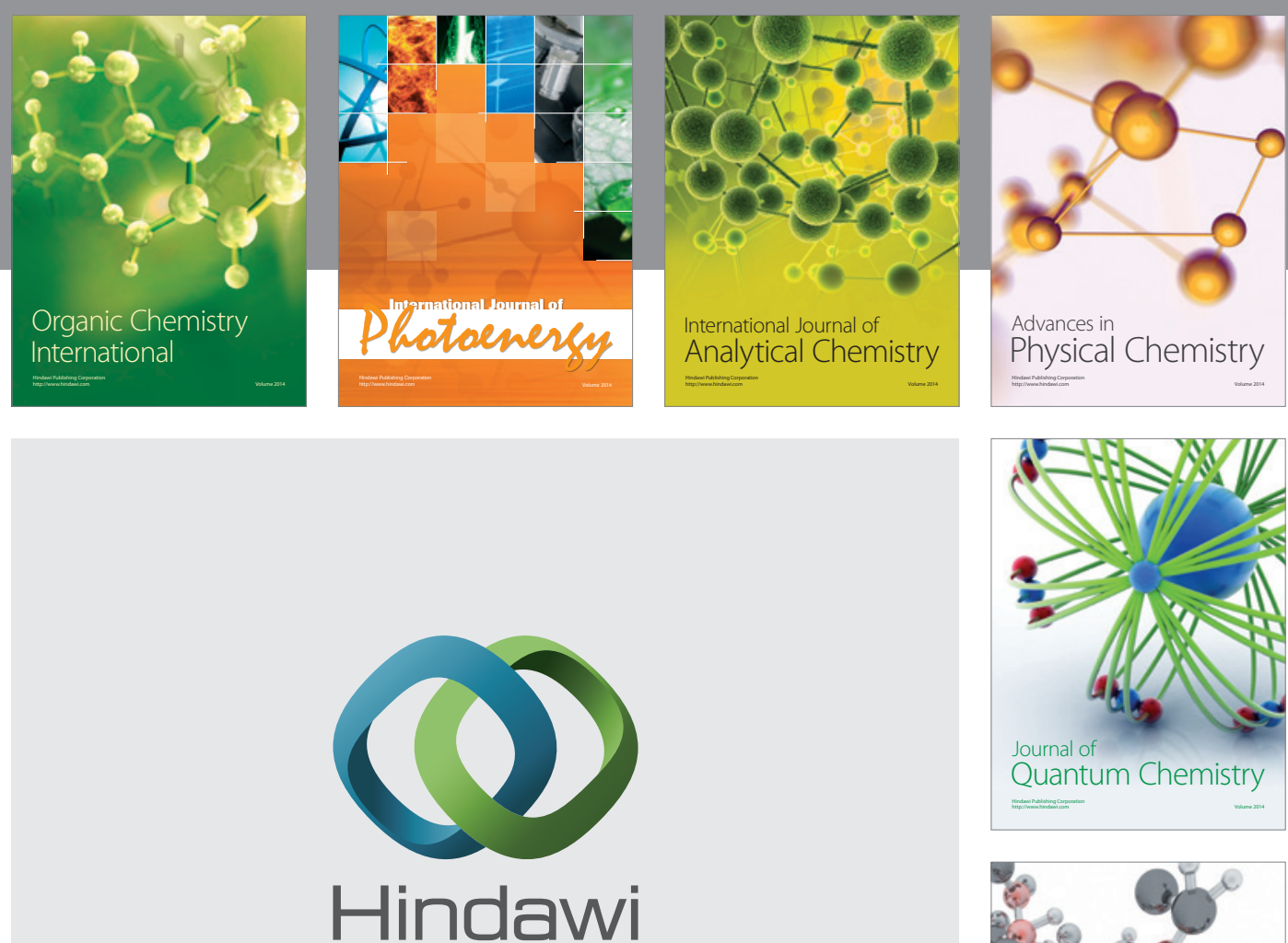

Submit your manuscripts at

http://www.hindawi.com

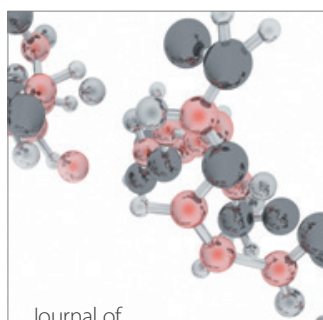

Analytical Methods

in Chemistry

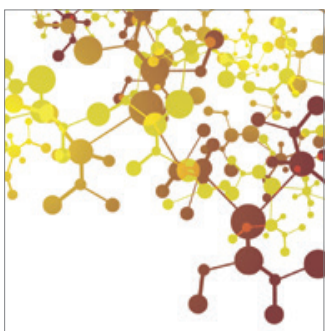

Journal of

Applied Chemistry

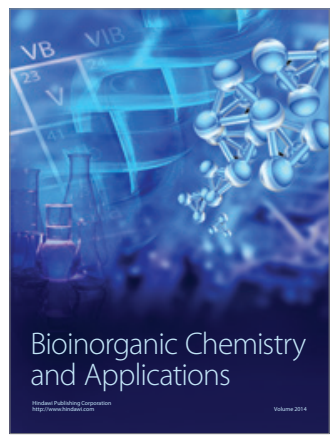

Inorganic Chemistry
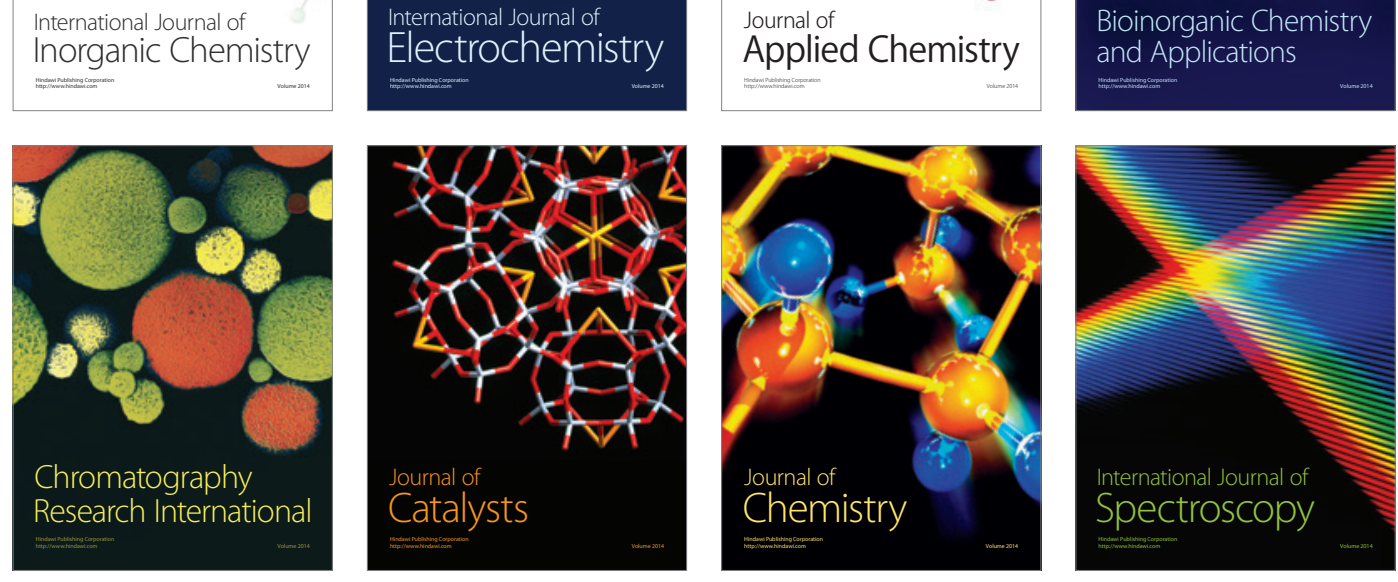